\title{
Knowledge of final-year medical students at the University of the Free State of hand hygiene as a basic infection control measure
}

\author{
M Bouwera, S Labuschagne ${ }^{a}$, S Spamera, C Vermaak ${ }^{a}$ iD, L-M Zietsman ${ }^{a}$ iD, D Steyn ${ }^{b^{*}}$ and G Joubert $^{c}$ \\ ${ }^{a}$ Faculty of Health Sciences, School of Medicine, University of the Free State, Bloemfontein, South Africa \\ ${ }^{b}$ Faculty of Health Sciences, Department of Internal Medicine, University of the Free State, Bloemfontein, South Africa \\ 'Faculty of Health Sciences, Department of Biostatistics, University of the Free State, Bloemfontein, South Africa \\ ${ }^{*}$ Corresponding author, email: SteynD@ufs.ac.za
}

Background: One of the main reasons for the spread of infection in the healthcare environment is inadequate hand hygiene. Poor knowledge of hand hygiene techniques leads to poor compliance. This study aimed to determine Free State University finalyear medical students' knowledge of hand hygiene as a basic infection control measure.

Methods: This was a cross-sectional study using self-administered anonymous questionnaires. The questions and memorandum were based on an extensive literature review with WHO documentation on the guidelines for hand hygiene in health care. Each participant received an envelope with an optical computer card, questionnaire and information document during a pre-arranged class. Participants recorded their answers on the card by shading in the squares corresponding to their responses.

Results: The average score of the 107 participants was $46.8 \%$ (range 10.1-73.6\%). Participants who felt that they had basic knowledge of hand hygiene $(n=32,30.5 \%)$ had an average score of $47.9 \%$. Participants with a self-reported knowledge level of more than basic but less than advanced $(n=56,53.3 \%)$ had an average score of $44.9 \%$ while those who reported advanced knowledge ( $n=17,16.2 \%)$ had an average score of 50.8\%. Three-quarters ( $n=81,77.1 \%)$ felt that their training was sufficient. Only $53.3 \%$ knew that the most important way to prevent the spread of infection is good hand hygiene. Only $10.5 \%$ of the students knew that hands should not be rinsed with water after using alcohol-based sanitisers.

Conclusion: Medical students have a poor level of knowledge regarding hand hygiene as a basic measure of infection control.

Keywords: hand hygiene, infection control, knowledge, medical students

\begin{abstract}
Introduction
In developing countries, up to $20 \%$ of hospitalised patients contract nosocomial infections, ${ }^{1}$ a major cause of increased morbidity, mortality and health costs. ${ }^{2}$ According to Trampuz and Widmer, ${ }^{3}$ the hands of healthcare workers are the primary way that these infections are spread. One of the main reasons for the spread of infection in the healthcare environment is inadequate hand hygiene. According to the World Health Organization (WHO), ${ }^{1}$ lack of knowledge of good hand hygiene practices is associated with poor compliance. In 2009, the WHO published its guidelines on hand hygiene in health care. ${ }^{1} \mathrm{~A}$ practical WHO brochure, 'Hand Hygiene: Why, How \& When', recommends that if hands are not visibly soiled, they should be rubbed with an alcohol-based formulation for 20 to 30 seconds and clear instructions are provided regarding proper rubbing. Visibly soiled hands should be washed with soap and water for 40 to 60 seconds with clear instructions regarding washing procedures. Hands should not be washed with soap and water immediately after or before using an alcohol-based handrub. Further guidelines are provided as to when hand hygiene is important.
\end{abstract}

A study in Saudi Arabia ${ }^{5}$ assessed medical students' knowledge and conduct regarding standard precaution and infection control. Most students (80.0\%) believed that there was an urgent need for training in infection control, and $61.4 \%$ felt that their current medical programme did not provide enough information. The knowledge they did have at the time was obtained from other sources, such as pamphlets, or following the consultants' example. Only $39.0 \%$ knew the correct duration of handwashing while $51.1 \%$ believed that alcohol-based products could replace basic handwashing. A third (33.5\%) agreed that handwashing was unnecessary when gloves are used.

Nair et al. ${ }^{6}$ assessed the knowledge of medical students and nurses in India using the WHO hand hygiene questionnaire for healthcare workers. Almost $80 \%$ of the participants reported that they had received formal training in hand hygiene. However, their level of knowledge was moderate (score 50-74\%) while only $9 \%$ had good knowledge (score $>75 \%$ ). Nurses were found to have significantly better knowledge compared with the medical students. Another study ${ }^{7}$ in India found that $58.2 \%$ of the medical students routinely used alcohol-based hand sanitisers but only $38.1 \%$ knew that it takes 20 seconds for these sanitisers to kill most microorganisms.

In a Namibian study ${ }^{8}$ on a convenience sample of health sciences students, medical students had a higher mean score (73\%) than nursing or radiology students regarding infection prevention and control. However, only $19.7 \%$ of medical students were reported to correctly specify the indications for alcohol-based hand sanitisers.

\section{Aim of the study}

To determine the level of knowledge of final-year medical students of the University of the Free State (UFS) of hand hygiene as a basic infection control measure.

\section{Method}

\section{Study design}

This was a cross-sectional study. 
Table 1: Knowledge of final-year medical students at the University of the Free State of hand hygiene as a basic infection control measure; only correct options are indicated $(n=105)$

\begin{tabular}{|c|c|}
\hline Factor & $n(\%)^{*}$ \\
\hline \multicolumn{2}{|l|}{ 1. The antimicrobial activity of alcohol results from the ability to: } \\
\hline Denature proteins & $53(50.5)$ \\
\hline \multicolumn{2}{|l|}{ 2. Which part of a patient's room is most densely and diversely colonised by microorganisms? } \\
\hline Doorknob & $49(46.7)$ \\
\hline \multicolumn{2}{|l|}{ 3. When using an alcohol-based hand sanitiser, what is the minimal time needed to kill most germs on your hands before rinsing with water? } \\
\hline None of the listed options (i.e. NOT 2; 8; 10; 20 seconds) & $11(10.5)$ \\
\hline \multicolumn{2}{|l|}{ 4. Which of the following methods of hand drying after a wash prevents contamination to the greatest degree in a hospital environment? } \\
\hline Paper towels & $51(48.6)$ \\
\hline \multicolumn{2}{|l|}{ 5. According to the World Health Organization (WHO), what should one do after using an alcohol-based hand sanitiser to prevent the formation of a biofilm? } \\
\hline $\begin{array}{l}\text { None of the listed options (i.e. NOT rinse hands with clean water; dry hands with sterile cloths; wash hands with soap and water; apply } 1 \% \text { chlorhexidine } \\
\text { and rinse with clean water) }\end{array}$ & $41(39.1)$ \\
\hline \multicolumn{2}{|l|}{ 6. Apart from the issue of skin tolerance and level of comfort, water temperature ... } \\
\hline Does not appear to be a critical factor for microbial removal from hands being washed & $21(20.0)$ \\
\hline \multicolumn{2}{|l|}{ 7. Clostridium difficile contaminated hand can easily be decontaminated with ... } \\
\hline Washing hands with water and soap & $52(49.5)$ \\
\hline \multicolumn{2}{|l|}{ 8. Which one of the following statements regarding hand hygiene is incorrect? } \\
\hline It is not necessary to wash your hands between patients during screening & $89(84.8)$ \\
\hline \multicolumn{2}{|l|}{ 9. Which statement is true about glove use? } \\
\hline It is necessary to discard gloves after each task & $83(79.1)$ \\
\hline \multicolumn{2}{|l|}{ 10. The efficiency of alcohol-based hand hygiene products is not affected by the following factor(s): } \\
\hline All of the above affects efficiency (percentage of alcohol in solution used; volume of alcohol used; whether hands are wet or dry when alcohol is applied) & $56(53.3)$ \\
\hline \multicolumn{2}{|l|}{ 11. Examination gloves are correctly used in which of the following statements: } \\
\hline During direct and indirect patient exposure (e.g. contact with blood/emptying emesis basins) & $73(69.5)$ \\
\hline \multicolumn{2}{|l|}{ 12. How are antibiotic-resistant pathogens most commonly spread from one patient to another in healthcare settings? } \\
\hline From one patient to another via hands of contaminated healthcare workers & $34(32.4)$ \\
\hline \multicolumn{2}{|l|}{ 13. What is the most frequent source of germs responsible for healthcare-associated infections with regard to cross-contamination? } \\
\hline Germs already present on or within the patient & $8(7.6)$ \\
\hline \multicolumn{2}{|l|}{ 14. According to the WHO, what is the single most important way to prevent the spread of disease in the hospital environment? } \\
\hline Handwashing & $56(53.3)$ \\
\hline \multicolumn{2}{|l|}{ 15. What should the temperature of water be when washing your hands? } \\
\hline Medium hot & $48(46.2)$ \\
\hline \multicolumn{2}{|l|}{ 16. What is a necessity when washing your hands? } \\
\hline Need to remove rings & $43(41.0)$ \\
\hline \multicolumn{2}{|l|}{ 17. The following hand condition can acquire and spread microorganisms the most readily: } \\
\hline Wet hands & $31(29.5)$ \\
\hline \multicolumn{2}{|l|}{ 18. Which of the following should be avoided, as recommended by the WHO, as it is associated with increased likelihood of colonisation of hands with harmful germs? } \\
\hline Both B and C (wearing of jewellery; wearing of long-sleeved white coats) & $45(42.9)$ \\
\hline \multicolumn{2}{|l|}{ 19. When a microbiologist swabs a patient's hand, the microorganism they would be able to find the most in terms of numbers is: } \\
\hline Staphylococcus epidermidis & $89(84.8)$ \\
\hline
\end{tabular}

*The results indicate $n(\%)$ students who chose the correct answer.

\section{Target population and sampling}

The target population was all 128 final-year medical students at UFS in 2015. Questionnaires were distributed to 107 students, as 21 students were busy with rotations elsewhere at the time of the study.

\section{Measurement}

Data were collected using an anonymous, self-administered questionnaire available in English. The questions and memorandum were based on an extensive literature review ${ }^{9,10-24}$ with WHO documentation on the guidelines for hand hygiene in health care as basis. ${ }^{1}$ Knowledge was tested by 20 multiplechoice questions of which one question had to be disregarded during the analysis due to incorrect formulation of the question. Participants recorded their answers on an optical computer card by shading in the squares corresponding to their responses.

\section{Data collection}

Each participant received a numbered envelope with a computer card, questionnaire and an information document during a prearranged class. Completed cards were sealed in the provided envelopes and collected by the student researchers. 
Table 2: Correct and most frequently chosen incorrect answer to questions where less than $40 \%$ of the students chose the correct option

\begin{tabular}{|c|c|}
\hline Item & $n(\%) *$ \\
\hline \multicolumn{2}{|l|}{ 3. When using an alcohol-based hand sanitiser, what is the minimal time needed to kill most germs on your hands before rinsing with water? } \\
\hline$\checkmark$ None of the listed options (i.e. NOT 2; 8; 10; 20 seconds) & $11(10.5)$ \\
\hline$\times 10$ seconds & $42(40.0)$ \\
\hline \multicolumn{2}{|l|}{ 5. According to the World Health Organization (WHO), what should one do after using an alcohol-based hand sanitiser to prevent the formation of a biofilm? } \\
\hline $\begin{array}{l}\checkmark \text { None of the listed options (i.e. NOT rinse hands with clean water; dry hands with sterile cloths; wash hands with soap and water; apply } 1 \% \text { chlorhex- } \\
\text { idine and rinse with clean water) }\end{array}$ & $41(39.1)$ \\
\hline$\times$ rinse hands with clean water & $23(21.9)$ \\
\hline \multicolumn{2}{|l|}{ 6. Apart from the issue of skin tolerance and level of comfort, water temperature ... } \\
\hline$\checkmark$ does not appear to be a critical factor for microbial removal from hands being washed & $21(20.0)$ \\
\hline $\begin{array}{l}\times \mathrm{A} \text { and } \mathrm{C} \text { is correct (does appear to be a critical factor for microbial removal from hands being washed AND does appear to influence the efficiency of } \\
\text { the antimicrobial activity of the antimicrobial agents used for hand washing purposes) }\end{array}$ & $53(50.5)$ \\
\hline \multicolumn{2}{|l|}{ 12. How are antibiotic-resistant pathogens most commonly spread from one patient to another in healthcare settings? } \\
\hline$\times$ Both A and D (airborne spread from patients coughing or sneezing AND from one patient to another via hands of contaminated healthcare workers. & $61(58.1)$ \\
\hline \multicolumn{2}{|l|}{ 13. What is the most frequent source of germs responsible for healthcare-associated infections with regard to cross-contamination? } \\
\hline$\checkmark$ Germs already present on or within the patient & $8(7.6)$ \\
\hline $\begin{array}{l}\times \text { All the above mentioned (the hospital's water system AND germs already present on or within the patient AND the hospital air (air conditioners includ- } \\
\text { ed) AND the hospital environment (surfaces)) }\end{array}$ & $46(43.8)$ \\
\hline \multicolumn{2}{|l|}{ 17. The following hand condition can acquire and spread microorganisms the most readily: } \\
\hline$\checkmark$ Wet hands & $31(29.5)$ \\
\hline$\times$ All of the above (hands with undamaged skin AND dry hands AND hands with gloves AND wet hands) & $58(55.2)$ \\
\hline
\end{tabular}

$\checkmark=$ correct answer; $x=$ most frequently chosen incorrect answer.

${ }^{*}$ Clinical significance:

20-30 seconds of alcohol-based hand rub (ABHR) recommended by the WHO constitute just a single step in hand hygiene but the optimal time is being challenged.

Rinsing hands with water or wiping them with a towel immediately after using ABHR might counteract the effect of the product. The benefit of AHBR is also lost since frequent hand washing with soap and water promote skin dryness and irritation.

Hot water promotes skin irritation and might not be readily available. It is reassuring and important to know that water temperature is of less importance.

The transmission of bacteria is more likely to occur from wet hands than from dry hands and proper drying of hands should therefore form an integral part of the hand hygiene process.

Knowing that HCW's hands is the most important source of the spreading of germs and the fact that most germs occur from patient's own colonization is critical important to understand to ensure that ABHR should be used before touching and after touching each patient.

\section{Pilot study}

A pilot study was done on 60 third-year UFS medical students. Errors in completing the cards included insufficient shading of squares, crossing out instead of erasing incorrect answers and not completing all the questions. This was addressed during the main study with clear instructions on how to complete the cards.

\section{Data analysis}

The computer cards were scanned by the Department of Information and Communication Technology Services, UFS. Data were analysed by the Department of Biostatistics, Faculty of Health Sciences, UFS, using SAS ${ }^{\oplus}$ version 9.3 (SAS Institute, Cary, NC, USA). Results are summarised by frequencies and percentages (categorical variables).

\section{Ethical aspects}

The protocol was approved by the Ethics Committee of the Faculty of Health Science, UFS [STUD NR 20/2015]. Permission for the study was obtained from the Dean of Faculty of Health Sciences, Head of School of Medicine, Vice-Rector Research and Dean of Student Affairs, UFS. Students were informed that participation was voluntary, that the participant could withdraw at any time and that completion of the test was taken as giving consent.

\section{Results}

Of the 107 questionnaires handed out, 105 (response rate 98.0\%) were completed and analysed (response rate out of total class of
128: $82.0 \%)$. The highest percentage of the 105 participants reported receiving formal training on hand hygiene as an infection control measure during their third year $(n=47,44.8 \%)$ and second year $(n=38,36.2 \%)$. Three-quarters ( $n=81,77.1 \%)$ felt that their training was sufficient. Almost all of the participants ( $n=101,96.2 \%)$ agreed that the prevalence of nosocomial infections in South Africa was rising.

Participants' average score was $46.8 \%$ (median $47.3 \%$, range $10.1-73.6 \%)$. Some $61 \%$ of participants scored $<50 \%$. Participants who felt that they had basic knowledge of hand hygiene $(n=32$, $30.5 \%$ ) had an average score of $47.9 \%$. Participants with a selfreported knowledge level of more than basic but less than advanced ( $n=56,53.3 \%$ ) had an average score of $44.9 \%$ while those who reported advanced knowledge $(n=17,16.2 \%)$ had an average score of $50.8 \%$. None of the students indicated that they had no knowledge of hand hygiene. Table 1 summarises the knowledge questions and correct answers.

Most students knew that gloves should be discarded after each task (79.1\%), that examination gloves are used during direct and indirect patient exposure (69.5\%), and that Staphylococcus epidermidis is present in high numbers on a swab taken of a patient's hand (84.8\%).

Table 2 constitute important and integral steps towards improving compliance with hand hygiene in clinical practice. For the six questions where less than $40 \%$ of the students chose the 
correct option, Table 2 indicates the most frequently chosen incorrect option. For three of these questions students mainly chose the option 'all/some of the above', which included the correct answers but also incorrect answers.

\section{Discussion}

Although $69.5 \%$ of the final-year medical students self-reported more than basic to advanced levels of knowledge and $77.1 \%$ were satisfied with the training they received in this regard, $61 \%$ failed the knowledge test. Nair et al. ${ }^{6}$ reported that $91.3 \%$ of participants felt they had sufficient knowledge on hand hygiene, but found that their actual knowledge was poor; for example, only $25.2 \%$ knew that it was necessary to wash hands prior to administering an injection. In a British study ${ }^{25}$ among third-year medical students, $83 \%$ of students reported receiving formal training on hand hygiene; however, large percentages did not know the correct indications for using alcoholic hand gel (58\%) or the correct use of hand gloves (35\%). In the current study, just $53.3 \%$ knew that, according to the $\mathrm{WHO}^{1}$ the single most important way to prevent the spread of disease in the hospital environment is good hand hygiene practices.

The majority of students agreed that the prevalence of nosocomial infections was increasing in South Africa. However, only $7.6 \%$ knew that the most frequent source of microorganisms responsible for these infections was the patients themselves. This is much lower than the $45 \%$ reported by Maheswari et al. ${ }^{26}$ Less than half of the final-year medical students knew that longsleeved white coats promote the spread of infections and that doorknobs have the highest load of microorganisms. According to the WHO, wearing long-sleeved coats should be avoided. ${ }^{1}$

In 2009, the WHO stated that alcohol-based hand sanitisers were one of the few fast and effective ways of inactivating a variety of potentially harmful microorganisms. In addition, it was suggested that these sanitisers be adopted as the gold standard for hand hygiene in health care. ${ }^{1}$ Our study found that only $10.5 \%$ of the students knew that hands should not be rinsed with water after using alcohol-based sanitisers, as this negatively affects the alcohol's antimicrobial activity. In comparison, Nair et al. ${ }^{6}$ reported that $46.3 \%$ of students were aware of this.

\section{Study limitations}

Questionnaires were completed at the start of the fifth year of training. Later during that year, students might receive further training in infection control. However, since they already had daily responsibilities in the hospitals, their level of knowledge at the time of the study raises concern.

\section{Conclusion}

Final-year medical students at the UFS have a poor level of knowledge regarding hand hygiene as a basic measure of infection control. Their understanding of alcohol-based sanitisers as an antimicrobial agent is poor. The students also have a misconception of their self-perceived level of knowledge.

\section{Recommendation}

We recommend that training on hand hygiene be extended to the fourth and fifth year of study. Clinical evaluations can include an infection control station to assess students' knowledge.

Disclosure statement - No potential conflict of interest was reported by the authors.
Acknowledgements - The authors wish to thank Ms J Jacobs, Information and Communication Technology Services, UFS, for scanning in the optical computer cards, and MsT Mulder, medical editor, School of Medicine, UFS, for technical and editorial preparation of the manuscript.

\section{ORCID}

C Vermaak (D) http://orcid.org/0000-0003-2246-4829

L-M Zietsman (D) http://orcid.org/0000-0003-0324-0037

\section{References}

1. World Health Organization. WHO guidelines on hand hygiene in health care: first global patient safety challenge clean care is safer care. Geneva: WHO Health Organization, Patient Safety; 2009.

2. Allegranzi B, Nejad S, Combescure C, et al. Burden of endemic healthcare-associated infection in developing countries: systematic review and meta-analysis. Lancet. 2011;377(9761):228-41. doi:10.1016/ S0140-6736(10)61458-4.

3. Trampuz A, Widmer AF. Hand hygiene: a frequently missed lifesaving opportunity during patient care. Mayo Clin Proc. 2004;79(1):109-16. doi:10.4065/79.1.109.

4. World Health Organization. Patient safety. Hand hygiene: why, how \& when. Geneva: WHO; 2009. [cited 2017 Oct 02]. Available from: http://who.int/gpsc/5may/Hand_Hygiene_Why_How_and_When_ Brochure.pdf

5. Amin TT, Al Noaim Kl, Bu Saad MA, et al. Standard precautions and infection control, medical students' knowledge and behavior at a Saudi university: the need for change. Glob J Health Sci. 2013;5(4):114-25. doi:10.5539/gjhs.v5n4p114.

6. Nair SS, Hanumantappa R, Hiremath SG, et al. Knowledge, attitude, and practice of hand hygiene among medical and nursing students at a tertiary health care centre in Raichur, India. ISRN Prev Med 2014;2014:608927. doi:10.1155/2014/608927.

7. Kamble VS, Biradar SM, Takpere A, et al. Knowledge of hand hygiene practices among students of ESIC medical college, Gulbarga, Karnataka, India. Int J Commu Med Publ Health. 2016;3(1):94-8. Available from https://doi.org/10.18203/2394-6040.ijcmph20151234..

8. Ojulong J, Mitonga $\mathrm{KH}$, lipinge SN. Knowledge and attitudes of infection prevention and control among health sciences students at University of Namibia. Afr Health Sci. 2013;13(4):1071-8. doi:10.4314/ ahs.v13i4.30

9. Ergin A, Bostanci M, Onal O, et al. Evaluation of students' social hand washing knowledge, practices, and skills in a university setting. Cent Eur J Public Health. 2011;19(4):222-6.

10. Baumgardner CA, Maragos CS, Walz J, et al. Effects of nail polish on microbial growth of fingernails. Dispelling sacred cows. AORN J. 1993;58(1):84-8. doi:10.1016/S0001-2092(07)65103-5.

11. Berardesca E, Vignoli GP, Distante F, et al. Effects of water temperature on surfactant-induced skin irritation. Contact Dermatitis 1995;32(2):83-7. doi:10.1111/j.1600-0536.1995.tb00751.x.

12. Fagernes $M$, Lingaas $E$, Bjark $P$. Impact of a single plain finger ring on the bacterial load on the hands of healthcare workers. Inf Cont Hosp Epidemiol. 2007;28(10):1191-5. doi:10.1086/520739.

13. Gustafson DR, Vetter EA, Larson DR, et al. Effects of 4 hand-drying methods for removing bacteria from washed hands: a randomized trial. Mayo Clin Proc. 2000;75(7):705-8. doi:10.1016/S0025-6196(11)64617-X.

14. Jacobson G, Thiele JE, McCune JH, et al. Handwashing: ring-wearing and number of microorganisms. Nurs Res. 1985;34(3):186-8. doi:10.1097/00006199-198505000-00012.

15. Kimel LS. Handwashing education can decrease illness absenteeism J School Nurs. 1996;12(2):14-6,18. https://doi.org/10.1177/10598405 9601200204

16. Larson EL, Morton HE. Alcohols. In: Block SS, editor. Disinfection, sterilization and preservation. 4th ed.. Philadelphia, PA: Lea \& Febiger; 1991:642-654.

17. Mackintosh CA, Hoffman PN. An extended model for transfer of micro-organisms via the hands: differences between organisms and the effect of alcohol disinfection. J Hygie. 1984;92(3):345-55. doi:10.1017/S0022172400064561. 
18. Marples RR, Towers AG. A laboratory model for the investigation of contact transfer of micro-organisms. J Hygie. 1979;82(2):237-48. doi:10.1017/S0022172400025651.

19. Ngeow YF, Ong HW, Tan P. Dispersal of bacteria by an electric air hand dryer. Malays J Pathol. 1989;11: 53-6.

20. Patrick DR, Findon G, Miller TE. Residual moisture determines the level of touch-contact-associated bacterial transfer following hand washing. Epidemiol Infect. 1997;119(3):319-25. doi:10.1017/ S0950268897008261.

21. Pittet D, Dharan S, Touveneau S, et al. Bacterial contamination of the hands of hospital staff during routine patient care. Arch Intern Med. 1999;159(8):821-6. doi:10.1001/archinte.159.8.821.

22. Pittet D, Tarara D, Wenzel RP. Nosocomial bloodstream infection in critically ill patients. Excess length of stay, extra costs, and attributable mortality. JAMA. 1994;271(20):1598-1601. Doi:10.1001/ jama.1994.03510440058033.
23. Rayan GM, Flournoy DJ. Microbiologic flora of human fingernails. J Hand Surg. 1987;12(4):605-7. doi:10.1016/S0363-5023(87)80217-4.

24. Vonberg RP, Kuijper EJ, Wilcox MH, et al. Infection control measures to limit the spread of Clostridium difficile. Clin Microbiol Infec. 2008;14(Suppl 5):2-20. doi:10.1111/j.1469-0691.2008.01992.x.

25. Mann CM, Wood A. How much do medical students know about infection control? J Hosp Infect. 2006;64(4): 366-70. doi:10.1016/j. jhin.2006.06.030.

26. Maheshwari V, Kaore NC, Ramnani VK, et al. A study to assess knowledge and attitude regarding hand hygiene amongst residents and nursing staff in a tertiary health care setting of Bhopal City. J Clin Diagn Res. 2014;8(8):DC04-7. doi:10.7860/JCDR/2014/8510.4696.

Received: 24-07-2017 Accepted: 22-10-2017 